www.jmscr.igmpublication.org

Impact Factor (SJIF): 6.379

Index Copernicus Value: 71.58

ISSN (e)-2347-176x ISSN (p) 2455-0450

crossref DOI: _https://dx.doi.org/10.18535/jmscr/v6i2.140

Journal Of Medical Science And Clinical Research

IGM Publication

An Official Publication of IGM Publication

\title{
Clonidine for alleviation of Propofol Induced Pain: A Prospective, Randomized, Double Blind Controlled Study
}

\author{
Authors \\ Dr Jhoshna Deverakonda ${ }^{1}$, Dr Somavarapu Sarwesh Kumar ${ }^{2}$, Dr Ramu Valluri ${ }^{3}$ \\ ${ }^{1,2}$ Assistant Professor, Kamineni Institute of Medical Sciences and Research Center, Hyderabad, Telangana \\ State, India \\ ${ }^{3}$ Professor and Head, Kamineni Institute of Medical Sciences and Research Center, Hyderabad, Telangana \\ State, India \\ Corresponding Author \\ Dr Somavarapu Sarwesh Kumar
}

Assistant Professor, Kamineni Institute of Medical Sciences and Research Center, Hyderabad, Telangana

State, India

Email: Dr.sbsarwesh.kimsrchyd@gmail.com

\begin{abstract}
Propofol, an intravenous anesthetic widely used for general anaesthesia cause severe pain in most of people. The aim of present study is to know the anti nociceptive effect of clonidine infusion with that of control (Normal saline) infusion immediately prior to propofol injection in alleviating Propofol injection pain (PIP). The present study was a randomized controlled study where in following the approval of the hospital's ethics Committee, 60 consenting adult patients were randomly divided into two groups $A$ and $B$ $(n=30)$ to receive $20 \mathrm{ml}$ of normal saline as control and $0.5 \mu \mathrm{g} / \mathrm{kg}$ of clonidine diluted in $20 \mathrm{ml}$ of normal saline respectively. The propofol injection pain was assessed according to the Mc Cririck and Hunter scale. The 27 patients in control group expressed pain compared to 18 patients in clonidine Group. In participants receiving clonidine 12(40\%) were determined to be in Grade 0 according to Mc.Crick and Hunter Pain Scale, 12(40\%) patients were determined to be in Grade 1 and 5(16.67\%) participants were in grade 2 followed by 1(3.33\%) patients were detrmined to be in Grade 3according to Mc.Crick and Hunter Pain Scale. There is no significant difference between heart rate, Mean Arterial Pressures and haemodynamic side effects in both groups. Pre treatment with0.5 $\mu \mathrm{g} / \mathrm{kg}$ of clonidine is effective in alleviating incidence and severity of propofol induced pain, did not cause significant hemodynamic adverse side effects.

Keywords: Propofol, Clonidine, Pain, Anaesthesia, Prevention, haemodynamic changes.
\end{abstract}

\section{Introduction}

Propofol is the most widely used intravenous (IV) induction agent worldwide owing to its smooth induction and rapid recovery characteristics. Propofol is the drug of choice for induction of anaesthesia in millions of patients every year because of its rapid onset and short duration of action, easy titration, and favourable profile for side effects ${ }^{[1]}$. Despite these positive attributes, about three out of five patients experience pain on 
injection of propofol, with one of these patients reporting severe or excruciating pain. Some patients recall the induction of anaesthesia as the most painful part of the perioperative period. As a result several interventions have been investigated to alleviate the pain associated with propofol injection $^{[2]}$.

The quality of pain was described as extremely sharp, aching, or burning. It has been arranged as the seventh most important problem in current practice of clinical anesthesia by American anesthesiologists $^{[3]}$. Many methods have been proposed to reduce the incidence of pain on propofol injection, including varying injection speed and carrier fluid, adjusting dilution temperature, and adding other concomitant drugs. Peripheral veins are innervated with polymodal nociceptors that mediate the responses to an injection that cause pain ${ }^{[4]}$. Pain on injection of propofol can be immediate or delayed. Immediate pain may result from a direct irritant effect, where as delayed pain may be caused by an indirect effect via kinin cascade ${ }^{[5,6]}$. A high concentration of free propofol in the aqueous phase of an emulsion activates the kallikreinkinin system in plasma, liberating bradykinin. Bradykinin acts on the local vein to dilate it and make it permeable. In this bradykinin-modified vein, the aqueous phase of propofol may contact more free nerve endings outside the endothelial layer of the vessel, causing pain ${ }^{[7]}$. Propofol injection pain (PIP), a well-known clinical phenomenon has an incidence ranging from $28 \%$ to $90 \%$ in adults ${ }^{[8]}$. Pain is one of the main pre-operative concerns among patients and analgesia is an important component of balanced anaesthesia technique. A number of techniques, both pharmacological and nonpharmacological, with varying efficacy have been tested and utilised to alleviate PIP.

Among a2-adrenergic receptor (a2-AR) agonists studied, Clonidine was found to alleviate the pain of injected propofol effectively ${ }^{[9]}$. It has also been widely used and investigated as an analgesic adjuvant for anaesthesia and pain therapy.
To compare the anti nociceptive effect of clonidine infusion with that of control immediately prior to propofol injection in alleviating Propofol injection pain (PIP). The objective of this study is to assess incidence and grade of propofol induced pain and arm withdrawal response, incidence of hemodynamic changes after single dose intravenous (iv) infusion of clonidine $0.5 \mu \mathrm{gms} / \mathrm{kg}$.

\section{Materials \& Methods}

The present study was conducted on patients admitted in in Kamineni Institute of Medical Sciences and research institute, Hyderabad, Telangana, undergoing elective surgeries under general anaesthesia after obtaining permission from the Institutional Ethical Committee. The participants were informed regarding the purpose, procedures, risks and benefits of the study. Written and Informed Consent was obtained from all participants.

The present study was conducted with a total of 60 participants; who were divided randomly into two groups. Group A comprised of 30 patients administered intravenous normal saline $20 \mathrm{ml}$ as control and Group B comprised of 30 patients administered intravenous Inj. clonidine $0.5 \mu \mathrm{gms} / \mathrm{kg}$ diluted in $20 \mathrm{ml}$ of normal saline. The present study was conducted from October 2015 to September 2017 i.e.two years. Inclusion criteria is patient willing to participate in surgery, Aged between 20 to 50 years, ASA I and II undergoing elective surgeries. Exclusion criteria is Patient's refusal to participate in study, allergy to the study drug, uncontrolled hypertension, renal or hepatic impairment, psychiatric diseases, seizures, history of drug abuse and Pregnancy. A detailed history of the patient was taken, complete clinical examination was done to include and exclude patients in accordance with the inclusion \& exclusion criteria. The investigations were performed on all participants. Pre operative assessment of temperature, pulse rate, respiratory rate, blood pressure and conditions of heart and lungs were noted. The non invasive arterial blood 
Pressure, ECG, Pulse Rate, SPO2 parameters were monitored in all participants intraoperatively.

An 18 Guage IV cannula was secured in the vein on the dorsum of the hand. Patients were randomly allocated into two groups (Group A and Group B). The study drugs, that is either inj Normal saline 20ml (Group A) or inj. clonidine $0.5 \mu \mathrm{gms} / \mathrm{kg}(($ diluted with $20 \mathrm{ml}$ Normal saline for Group B) were loaded in identical $20 \mathrm{ml}$ syringes labeled as "study drug" and infused over 10 minutes.

Immediately after infusion of the study drug, injection Propofol $2 \mathrm{mg} / \mathrm{kg}$ IV was administered slowly over 25 seconds. Starting from the time of injection, participants were assessed for pain by asking "does it hurt?" every 5 seconds, until the participant became unresponsive. Degree of pain was scored with Mc.Cririck and Hunter scale which was mentioned below.

Table 1 Mc.Cririck and Hunter scale

\begin{tabular}{|l|c|c|}
\hline Score & Response & Interpretation \\
\hline 0 & Negative response (no) to question & No pain \\
\hline 1 & $\begin{array}{c}\text { Pain reported "yes" only in } \\
\text { response to the question without } \\
\text { any behavioural changes }\end{array}$ & Mild pain \\
\hline 3 & $\begin{array}{c}\text { Voluntary complaint of pain or } \\
\text { behavioural changes }\end{array}$ & Moderate pain \\
\hline $\begin{array}{c}\text { Strong vocal response or facilal } \\
\text { grimacing or arm withdrawl or } \\
\text { tears on injection }\end{array}$ & Severe pain \\
\hline
\end{tabular}

Patients were monitored for hemodynamic effects. Mean arterial blood pressure (MAP) and heart rate (HR) were measured at 2-minute intervals from just before the administration of study drug to 10 minutes after the tracheal intubation (following Inj. Succinylcholine $1-2 \mathrm{mg} / \mathrm{kg}$ ). It was followed by a standard technique consisting of Inj. Fentanyl 1-2 $\mathrm{mg} / \mathrm{kg}$, glycopyrrolate $0.2 \mathrm{mg}$ and inj. vecuronium as appropriate for the weight of the patient. Anaesthesia was maintained with nitrous oxide and oxygen. Any episode of bradycardia (HR $<60 /$ min or a fall of $>20 \%$ from basal HR), hypotension (mean atrial pressure $<60 \mathrm{~mm} \mathrm{Hg}$ or a fall of $>20 \%$ from basal BP), hypertension or tachycardia (rise of $>20 \%$ from basal values) were recorded and managed as per the standard protocols

\section{Statistical Analysis}

Statistical testing was conducted with the MS Excel and statistical package for the social sciences version (SPSS) version 20.0. Sociodemographic data i.e. age, weight, height and body mass index (BMI) and baseline vital parameters are presented as mean $( \pm$ standard deviation) and were compared utilising the unpaired Student's $t$-test. Categorical variables are expressed as frequencies and percentages and were compared using Chi-square test. For all statistical tests, $P$ value of $<0.05$ was taken as significant.

\section{Results}

The present study was conducted in a sample of 60 participants, who were randomly divided into two groups, comprising of 30 participants each, Group A (Control) $\quad(n=30)$ and Group B (Clonidine) $(n=30)$. The results are as follows:

\section{Demographic characteristics}

Comparison of the demographic characteristics are depicted in Table 1.

Age

The mean age in group A was observed to be $32.43( \pm 10.20)$ yrs and in Clonidine group it was observed to be $35.60( \pm 12.10)$ yrs. The difference in the mean age of the two study groups was not found to be statistically significant. $(\mathrm{P}>0.05)$ Thus, the two study groups were observed to be comparable in terms of their age.

Table 2: Comparison of Demographic \& Other Characteristics between the Study Groups

\begin{tabular}{|l|l|l|}
\hline Characteristic & GroupA (N=30) & Group B (N=30) \\
\hline $\begin{array}{l}\text { Age (yrs)(Mean+- } \\
\text { SD) }\end{array}$ & $32.43( \pm 10.20)$ & $35.60( \pm 12.10)$ \\
\hline Gender (M/F) & $14 / 16$ & $16 / 14$ \\
\hline $\begin{array}{l}\text { Weight (kg) } \\
(\text { Mean+-SD) }\end{array}$ & $55.27( \pm 7.83)$ & $57.8( \pm 7.57)$ \\
\hline ASA status (I/II) & $27 / 3$ & $28 / 2$ \\
\hline
\end{tabular}

SD: standard deviation; ASA status: American society of Anesthesiologist-physical status 


\section{Gender}

Control Group was observed to comprise of 14(46.67 \%) males and 16(53.33\%) females. Clonidine Group was observed to comprise of $16(53.33 \%)$ males and 14(46.67 \%) females. The difference in gender of participants of the two study groups was not found to be statistically significant. $(\mathrm{P}>0.05)$ and the two study groups were observed to be comparable in terms of gender.

\section{Weight}

The mean weight in control group B was observed to be $55.27( \pm 7.83) \mathrm{kg}$ and in Clonidine group, it was observed to be $57.5( \pm 7.57) \mathrm{kg}$. The difference in the mean weight of the two study groups was not found to be statistically significant. $(\mathrm{P}>0.05)$ and the two study groups were thus observed to be comparable in terms of their weight.

\section{ASA Status}

Control Group A was observed to comprise of 27 patients classified as ASA-I status and 3 patients classified as ASA-II status. Clonidine Group was observed to comprise of 28 patients classified as ASA-I status and 2 patients classified as ASA-II status. The difference in ASA status between the two groups was not found to be statistically significant. $(\mathrm{P}>0.05)$ and the two study groups were thus observed to be comparable in terms of their ASA physical status.

\section{Incidence of Pain and Severity Of Pain on Propofol Injection (PIP)}

The 27 patients in control group expressed pain compared to 18 patients in clonidine Group. In participants receiving clonidine 12(40\%) were determined to be in Grade 0 according to Mc.Crick and Hunter Pain Scale,12(40\%) patients were determined to be in Grade 1 and 5(16.67\%) participants were in grade 2 followed by $1(3.33 \%)$ patients were detrmined to be in Grade 3according to Mc.Crick and Hunter Pain Scale.
Table 3: Effectiveness of Clonidine in Reducing Propofol Induced Pain (PIP) among the two study groups

\begin{tabular}{|l|c|c|}
\hline $\begin{array}{l}\text { Mc.Crick and Hunter } \\
\text { Pain Scale }\end{array}$ & $\begin{array}{c}\text { Control Group } \\
(\mathrm{N}=30)\end{array}$ & $\begin{array}{c}\text { Clonidine Group } \\
(\mathrm{N}=30)\end{array}$ \\
\hline Grade 0 & $3(10)$ & $12(40)^{*}$ \\
\hline Grade 1 & $8(27)$ & $12(40)^{*}$ \\
\hline Grade 2 & $15(50)$ & $5(16.67)^{*}$ \\
\hline Grade 3 & $4(13)$ & $1(3.33)^{*}$ \\
\hline Total & $30(100)$ & $30(100)$ \\
\hline
\end{tabular}

$\mathrm{P}<0.05$ *: Significant

\section{Hemodynamic Parameters}

The heart rate (HR), systolic and diastolic blood pressure, Mean arterial pressure (MAP) of the study participants were monitored preoperatively (baseline), time of injection of the study drugs, and till after 2, 4,6,8,10,12,14,16,18 and 20 minutes after injection minutes after administration of study drugs in both groups (Groups A \& B).

\section{Heart rate}

The mean baseline heart rate was observed to be $84.52( \pm 13.22)$ and $82.33( \pm 10.20)$ bpm in control group and Clonidine group respectively. After start of infusion of clonidine, HR was observed to decrease to 78.83 ( \pm 13.39 ), in Group A. After 2 minutes, it was $(79.4 \pm 12.89) \mathrm{bpm}$ and it was $80.01( \pm 14.03) \mathrm{bpm}$ after 4 minutes. Thereafter it showed a slight increase at 6 minutes to $81.97( \pm 16.32) \mathrm{bpm}$ and was observed at 10 minutes at a mean of $82.2( \pm 14.64)$ bpm. At 12 minutes an increase in the mean HR was observed at $93.7( \pm 12.84)$ bpm which declined to 86.03 (+14.64) bpm at 14 minutes. At 16 minutes it decreased to $86.03( \pm 11.63)$ beyond which it was observed to attain a mean of $83.3( \pm 11.63)$ at 18 and $83.65( \pm 10.48)$ at 20 minutes respectively. In control group it was almost equal to base line up to first $10 \mathrm{~min}$ and after propofol it was decreased upto $16 \mathrm{~min}$ and comes to normal at $20 \mathrm{~min}$, hence heart rates are comparable in two groups.

\section{Mean Arterial Pressure}

The mean baseline Mean arterial pressure was observed to be $90.77( \pm 18.59) \mathrm{mmHg}$ in Clonidine group and was observed to be $97.83( \pm 10.27)$ $\mathrm{mmHg}$ in control group. At baseline, the Mean 
arterial pressure in both groups was found to be comparable. i.e. the difference in the mean arterial pressure between the two study groups was not found to be significant statistically. $(\mathrm{P}>0.05)$

After start of infusion of MAP was observed to decrease to a mean of $(99.20 \pm 12.85) \mathrm{mmHg}$ at $12 \mathrm{~min}$ and it decreased further to $98.57( \pm 13.64)$ $\mathrm{mmHg}$ after 14 minutes. Thereafter it showed a slight increase at 16 minutes to $99.03( \pm 14.29)$ $\mathrm{mmHg}$ and at 20 minutes a mean MAP of 99.63 $( \pm 17.64) \mathrm{mmHg}$ was observed.

After start of infusion of clonidine, MAP was observed to increase to $92.37( \pm 8.54) \mathrm{mmHg}$ in Group A. After 2 minutes, it was observed to decrease to a mean of $90.87( \pm 10.75) \mathrm{mmHg}$; it increased to a mean of $94.43( \pm 9.73) \mathrm{mmHg}$ after 4 minutes. Thereafter it showed a slight increase at 6 minutes to $95.60( \pm 13.87) \mathrm{mmHg}$ and at 10 minutes a mean MAP of $95.23( \pm 17.63) \mathrm{mmHg}$ was observed. At 12 minutes; a decrease in the mean MAP was observed at $93.07( \pm 11.93) \mathrm{mmHg}$ which increased to $92.33( \pm 12.41) \mathrm{mmHg}$ at 14 minutes. At 16 minutes, a decrease was observed to $90.13( \pm 9.30) \mathrm{mmHg}$ beyond which it was observed to decrease further and attain a mean of $89.43( \pm 10.16) \mathrm{mmHg}$ at 18 and $89.43( \pm 10.09)$ $\mathrm{mmHg}$ at 20 minutes respectively.

The difference in mean arterial pressure among both the groups was not found to be significant at all observed points of time after infusion of the study drug.(p>0.05).

\section{Hemodynamic Side Effects}

The side effects were comparable in 2 groups and there is no significant difference between the two goups.

Table 4: Incidence of side effects in groups

\begin{tabular}{|l|c|c|}
\hline Incidence & $\begin{array}{c}\text { Control G } \\
\text { Of Side Effects }\end{array}$ & $\begin{array}{c}\text { Clonidine G } \\
(\mathrm{N}=30) \\
\mathrm{N}(\%)\end{array}$ \\
\hline Present & $3((10)$ & $2(6.67)$ \\
\hline Absent & $27(90)$ & $28(93.33)$ \\
\hline Total & $30(100)$ & $30(100)$ \\
\hline
\end{tabular}

Table 5: Hemodynamic Side Effects in Study

\begin{tabular}{|l|c|c|}
\hline Side effects & $\begin{array}{c}\text { Control A } \\
(\mathrm{N}=30) \\
\mathrm{N}(\%)\end{array}$ & $\begin{array}{c}\text { Clonidine B } \\
(\mathrm{N}=30) \\
\mathrm{N}(\%)\end{array}$ \\
\hline None & $27(90.00)$ & $28(93.33)$ \\
\hline Hypotension & $2(6.66)$ & $1(3.33)$ \\
\hline Hypertension & 0 & $1(3.33)$ \\
\hline Bradycardia & $1(3.33)$ & $0(0)$ \\
\hline Total & $30(100)$ & $30(100)$ \\
\hline
\end{tabular}

\section{Discussion}

Propofol, an excellent IV anesthetic belonging to the phenol group, can irritate the skin, the mucous membrane, and the venous intima. The mechanism of pain is attributed to the activation of the kinin-kallikrein system that releases bradykinin, causing vasodilatation and hyper permeability, thereby increasing contact between the aqueous phase propofol and the free nerve endings ${ }^{[10]}$. Considering the extensive use of propofol in clinical practice, the pain frequently reported on induction of anesthesia cannot be neglected. Although it is not a serious complication, efforts are assumed to reduce the severity of the pain or discomfort. Propofol belongs to the group of phenols that can irritate the skin, mucous membranes, and venous intima $^{[11]}$. Injection pain associated with propofol characteristically occurs immediately or later after the drug injection with a delayed response of 10$20 \mathrm{~s}^{[12]}$. The explanation for the pain includes endothelial irritation, osmolality differences, unphysiological $\mathrm{pH}$,and the activation of pain mediators ${ }^{[13]}$.

Many methods have been used to reduce the incidence of pain on propofol injection with variable results.

Clonidine is an imidazoline compound with the molecular formula $\mathrm{C} 9 \mathrm{H} 9 \mathrm{Cl} 2 \mathrm{~N} 3$. It is the prototype of alpha-2 adrenoceptor agonists with an alpha-2: alpha-1 ratio of 200:11. These properties along with its ability to maintain peri-operative haemodynamic stability make clonidine a useful agent in anaesthesia and intensive care. Clonidine acts by stimulating the pre-synaptic alpha 2 adrenoceptors, thereby decreasing noradrenaline release from both central and peripheral 
sympathetic nerve terminals. The effects of clonidine occur due to its action both at spinal and supraspinal sites, including depression of thalamic transmission of impulses to the cerebral cortex as well as enhancement of descending inhibitory pathways to the dorsal horn ${ }^{[14]}$.

Clonidine markedly decreases noradrenaline concentrations in the locus coeruleus. The efferents from the locus coeruleus act on the descending fibres of the reticulospinal tracts that inhibit pain transmission at the spinal level ${ }^{[15]}$ Alpha 2 adrenoceptors are found post junctionally on the dorsal horn neurons of the spinal cord and acts by inhibiting the release of substance P.Clonidine also acts on the cholinergic, purinergic and serotonergic pain systems causing analgesia $^{[16]}$.

It is an analgesic, sedative and anxiolytic ${ }^{[14]}$. Along with local anaesthetic agents, it is an adjunct in regional anaesthesia and in the treatment of chronic pain ${ }^{[16]}$.

Yoshikawa $\mathrm{T}$ et $\mathrm{al}^{[9]}$. examined the analgesic effects of orally administered clonidine on pain induced by injection of propofol (Diprivan; 2,6diisopropyl phenol). Female patients $(n=81)$ were randomly allocated to one of two groups: oral clonidine (5.5 microg $\mathrm{kg}(-1)$ ) followed by i.v. propofol and a control group given placebo followed by i.v. propofol. The median pain score in the group receiving clonidine, using a fourpoint scale $(0=$ no pain, $1=$ minimal pain, $2=$ moderate pain, $3=$ severe pain) was $1(0-2)$, was observed to be significantly lower in the group receiving clonidine than in the control group [2 (13 ), median (25-75 percentiles), $\mathrm{P}<0.001]$. Their results is consistent with our results in Clonidine group.

Ishiyama $\mathrm{T}$ et $\mathrm{al}^{[17]}$ evaluated the effects of clonidine and ephedrine on propofol-induced pain and on hemodynamic changes during the induction sequence in their study. The four study groups were: clonidine-ephedrine (CE), clonidinesaline (CS), diazepam-ephedrine (DE), and diazepam-saline (DS)
Median pain score in CE was significantly lower than those in the other groups $(P<0.0001)$. Pain scores in CS and DE were significantly lower than that in DS $(P<0.05)$. Ephedrine increased HR in $\mathrm{CE}$ and DE $(P<0.05)$, but clonidine did not augment the effect. Mean arterial blood pressure before tracheal intubation decreased to comparable values in all groups. Their results in clonidine group was found to be comparable to our results.

\section{Conclusion}

The results of the present study show that 0.5 $\mu \mathrm{g} / \mathrm{kg}$ of clonidine is effective in alleviating incidence and severity of propofol induced pain, did not cause significant hemodynamic adverse side effects.

\section{References}

1. Marik PE; Propofol: therapeutic indications and side-effects. Curr Pharm Des2004;10:3639-49

2. Jalota L, Kalira V, George E, Shi YY, Hornuss C, Radke O, Apfel CC; Prevention of pain on injection of propofol: systematic review and metaanalysis.Bmj, 2011; 342.

3. Macario A, Weinger M, Truong P, Lee M; Which clinical anesthesia outcomes are both common and important to avoid? The perspective of a panel of expertanesthesiologists. Anesth Analg, 1999; 88:1085-1091.

4. Arndt JO, Klement W; Pain evoked by polymodal stimulation of hand veins in humans. J Physiol,1991; 440: 467-478.

5. Briggs LP, Clarke RSJ, Dundee JW, Moore J, Bahar M, Wright PJ; Use of diisopropyl phenol as main agent for short procedures. British journal of anaesthesia, 1981; 53(11): 1197-1202.

6. Nakane $\mathrm{M}$, Iwama $\mathrm{H} ; \mathrm{A}$ potential mechanism of propofol-induced painon injection based on studies using 
nafamostat mesilate. Br J Anaesth, 1999; 83:397-404.

7. Doenicke AW, Roizen MF, Rau J, Kellermann W, Babl J; Reducing pain during propofol injection: The role ofthe solvent. Anesth Analg, 1996; 82:472-474.

8. Ahmed A, Sengupta S, Das T, Rudra A, Iqbal A. Pre-treatment with intravenous granisetron to alleviate pain on propofol injection: A double-blind, randomized, controlled trial. Indian J Anaesth. 2012; 56:135-8.

9. Yoshikawa T, Wajima Z, Ogura A, Inoue T, Ogawa R. Orally administered clonidine significantly reduces pain during injection of propofol. Br J Anaesth. 2001;86:874-6.

10. Nakane $M$, Iwama $H$; A potential mechanism of propofol-induced painon injection based on studiesusing nafamostat mesilate. Br J Anaesth, 1999; 83: 397-404

11. Ambesh SP, Dubey PK, Sinha PK; Ondansetron pre treatment to alleviate pain on propofol injection:A randomized, controlled, double-blindedstudy. Anesth Analg, 1999; 89: 197-199.

12. Briggs LP, Clarke RSJ, Dundee JW, Moore J, Bahar M, Wright PJ; Use of diisopropyl phenol as main agent for short procedures. British journal of anaesthesia, 1981; 53(11): 1197-1202.

13. Stokes DN, Robson N, Hutton P; Effect of diluting propofol on the incidence of pain on injection and venous sequelae. $\mathrm{Br} \mathrm{J}$ Anaesth, 1989; 62: 202-203

14. Jamadarkhana S, Gopal S. Clonidine in Adults as a Sedative Agent in the Intensive Care Unit. Journal of Anaesthesiology, Clinical Pharmacology 2010;26(4):439445.

15. Martin Sasada, Susan Smith. 3rd. Oxford (UK): Oxford University Press; 2003. Drugs in Anaesthesia and Intensive care; pp. 76-77.

16. Maze M, Tranquilli W. Alpha 2 adrenoceptor agonists: defining the role in clinical

anaesthesia. Anesthesiology. 1991;74:581-605.

17. Ishiyama $\mathrm{T}$, Kashimoto $\mathrm{S}$, Oguchi $\mathrm{T}$, Furuya A, Fukushima H, Kumazawa T. Clonidine-ephedrine combination reduces pain on injection of propofol and blunts hemodynamic stress responses during the induction sequence. $\mathrm{J}$ Clin Anesth 2006;18:211-5. 